nephron

Practice

\title{
UK Renal Registry 18th Annual Report: Chapter 10 Clinical, Haematological and Biochemical Parameters in Patients Receiving Renal Replacement Therapy in Paediatric Centres in the UK in 2014: National and Centre-specific Analyses
}

\author{
Alexander J Hamilton ${ }^{a}$, Fiona Braddon ${ }^{a}$, Anna Casula ${ }^{a}$, Carol Inward ${ }^{b}$, Malcolm Lewis ${ }^{c}$, \\ Tamara Mallett ${ }^{\mathrm{b}}$, Heather Maxwell ${ }^{\mathrm{d}}$, Catherine $\mathrm{O}^{\prime}$ Brien $^{\mathrm{e}}$, Yincent Tse ${ }^{\mathrm{f}}$, Manish D Sinha ${ }^{\mathrm{g}}$ \\ ${ }^{a}$ UK Renal Registry, Bristol, UK; ${ }^{b}$ Bristol Royal Hospital for Children, Bristol, UK; ${ }^{\circ}$ Royal Manchester Children's Hospital, \\ Manchester, UK; ${ }^{d}$ Royal Hospital for Children, Glasgow, UK; ${ }^{~}$ Birmingham Children's Hospital, Birmingham, UK; \\ fGreat North Children's Hospital, Newcastle Upon Tyne, UK; ${ }^{9}$ Evelina London Children's Hospital, London, UK
}

\section{Key words}

Adolescents - Biochemical variables - Blood pressure - BMI . Children . Dialysis . Established renal failure . Growth . Haemoglobin · Height · Hypertension · Paediatric · Quality improvement - Renal replacement therapy - Transplant . Weight $\cdot$ Young adults

\section{Summary}

- The median height $\mathrm{z}$-score for paediatric patients on dialysis was -2.1 and for those with a functioning transplant -1.3 . Children transplanted before the age of 12 years improved their height $\mathrm{z}$-score over the subsequent five years, whereas those older than 12 maintained their height $\mathrm{z}$-score, with all transplanted patients having a similar median height $\mathrm{z}$-score after five years of starting renal replacement therapy (RRT).

- The median weight $\mathrm{z}$-score for children on dialysis was -1.4 whereas children with a functioning transplant had a near normal weight for age and sex with a median $\mathrm{z}$-score of -0.3 .
- Of those with data, $75 \%$ of the prevalent paediatric RRT population had one or more 'traditional' risk factors for cardiovascular disease, with 1 in 10 having all three risk factors present.

- For the 10 centres reporting quarterly laboratory data, the average creatinine in transplant patients was $79 \mu \mathrm{mol} / \mathrm{L}$; dialysis patients had normal average anaemia and acidosis markers and evidence of secondary hyperparathyroidism with an average PTH of $17.3 \mathrm{pmol} / \mathrm{L}$.

- For transplant patients, $80 \%$ achieved the systolic blood pressure (SBP) standard and 93\% achieved the haemoglobin standard.

- For haemodialysis patients, 57\% achieved the SBP standard, $62 \%$ achieved the haemoglobin standard, $82 \%$ achieved the calcium standard, 51\% achieved the phosphate standard and 39\% achieved the parathyroid hormone (PTH) standard.

- For peritoneal dialysis patients, $70 \%$ achieved the SBP standard, $77 \%$ achieved the haemoglobin standard, $72 \%$ achieved the calcium standard, 54\% achieved the phosphate standard and 33\% achieved the PTH standard.

\section{KARGER}

Fax +4161306 1234 E-Mail karger@karger.com www.karger.com/nef
(C) 2016 The UK Renal Registry Published by S. Karger AG, Basel $1660-8151 / 16 / 1325-0237 \$ 39.50 / 0$

Karger Open access

This article is licensed under the Creative Commons AttributionNonCommercial-NoDerivatives 4.0 International License (CC BYNC-ND) (http://www.karger.com/Services/OpenAccessLicense). Usage and distribution for commercial purposes as well as any distribution of modified material requires written permission.
Alexander Hamilton

UK Renal Registry, Southmead Hospital, Southmead Road Bristol, BS10 5NB, UK

Email: renalregistry@renalregistry.nhs.uk 


\section{Introduction}

This Report focuses on the following variables for the prevalent paediatric dialysis and transplantation cohort on the 31st December 2014:

1. The completeness of data returns to the UK Renal Registry (UKRR)

2. Anthropometric characteristics and growth

3. Cardiovascular risk factors (CVRFs)

4. Laboratory and clinical indices including anaemia control and biochemical findings

Analyses of prevalent paediatric patients aged $<18$ years receiving renal replacement therapy (RRT) for the year 2014 and for the period 2003 to 2014 inclusive are reported. A single dataset was collected for each patient per year during this time period. Where possible, analysis of incident cohorts has been undertaken with centre specific data for each paediatric nephrology centre in the UK also being provided.

In previous years the analyses have been restricted to those aged under 16 years, this year those aged 16-18 years are also included.

\section{Methods}

Processes for data collection for the paediatric UKRR are described in chapter 4 . The data presented in this Report relate to the annual census date of 31st December 2014.

Standards and standardisation

Standards are in bold text and are from the 'Treatment of adults and children with renal failure', Renal Association standards third edition (2002) [1] unless otherwise stated.

Where the value of clinical parameters in childhood varies with age, sex and size, data are presented as z-scores.

\section{Anthropometry}

'Measures of supine length or standing height and weight should be monitored at each clinic visit. All measurements should be plotted on European reference growth charts for healthy children.'

The reference range for height $(\mathrm{Ht})$, weight $(\mathrm{Wt})$ and body mass index (BMI) in childhood varies with gender and age. BMI was calculated using the formula $\mathrm{BMI}=\mathrm{Wt}(\mathrm{kg}) / \mathrm{Ht}^{2}$ (m). Height and weight were adjusted for age. To account for discrepancies in linear growth secondary to renal disease, BMI was expressed according to height-age, rather than chronological age. The International Obesity Taskforce definition [2] was used to define overweight and obesity; z-scores were calculated based on the British 1990 reference data for height and weight [3].
Blood pressure

'Blood pressure varies throughout childhood and should be maintained within two standard deviations of the mean for normal children of the same height and sex. The systolic blood pressure during peritoneal dialysis or after haemodialysis should be maintained at $<90$ th centile for age, gender and height.'

'In paediatric renal transplant patients, the systolic blood pressure should be maintained at $<90$ th percentile for age, gender and height.'

The analyses of systolic blood pressure (SBP) in this Report present the achievement of SBPs at or below the 90th percentile. Guidance for blood pressure in paediatric renal transplant patients was based on 2011 British Association for Paediatric Nephrology recommendations [4].

The reference range for SBP varies with gender, age and height. The data is therefore presented as $\mathrm{z}$-scores based on data from the fourth report of the National High Blood Pressure Education Programme working group in the United States [5].

\section{Cholesterol}

The National Heart Lung and Blood Institute recommends screening for dyslipidaemias in children with chronic kidney disease/established renal failure/post renal transplant (deemed high risk) between the ages of 2 and 17, and defines high total cholesterol as $\geqslant 5.2 \mathrm{mmol} / \mathrm{L}$ [6]. This cut-off has been adopted for this Report.

\section{Haemoglobin $(\mathrm{Hb})$ and Ferritin}

Guidance on the management of anaemia in adults and children with chronic kidney disease was updated and published by the National Institute for Health and Care Excellence in February 2011 (Clinical Guideline 114) [7].

'Typically maintain the aspirational $\mathrm{Hb}$ range between 100 and $120 \mathrm{~g} / \mathrm{L}$ for young people and children aged 2 years and older, and between 95 and $115 \mathrm{~g} / \mathrm{L}$ for children younger than 2 years of age, reflecting the lower normal range in that age group.'

Haemoglobin and ferritin were analysed using age related laboratory reference ranges as in table 10.1.

\section{Calcium, phosphate and parathyroid hormone (PTH)}

'Serum phosphate and calcium should be kept within the normal range. PTH levels should be maintained within twice the upper limit of the normal range but, contrary to adult standards, may be kept within the normal range if growth is normal.'

Calcium, phosphate and PTH were analysed using age related laboratory reference ranges as in table 10.1. Individual variable data analysis has been performed per centre and nationally. It should be noted that 'normal' growth is difficult to determine in the setting of paediatric RRT.

Bicarbonate

'Serum bicarbonate concentrations should be between 20 and $26 \mathrm{mmol} / \mathrm{L}$.'

Bicarbonate reference ranges vary by centre, and are reported as within or outside the reference range as given in table 10.1. 
Table 10.1. Summary of relevant biochemical clinical audit measures

\begin{tabular}{|c|c|c|c|c|}
\hline \multirow[b]{2}{*}{ Parameter } & \multicolumn{4}{|c|}{ Age } \\
\hline & $<1$ year & $1-5$ years & $6-12$ years & $>12$ years \\
\hline Haemoglobin (g/L), NICE guideline CG 114 & $\begin{array}{l}\text { Maintain } 95-115 \\
\text { if aged }<2 \text { years }\end{array}$ & $\begin{array}{l}\text { Maintain } 100-120 \\
\text { if aged }>2 \text { years }\end{array}$ & $100-120$ & $100-120$ \\
\hline Ferritin $(\mu \mathrm{g} / \mathrm{L})$ & $200-500$ & $200-500$ & $200-500$ & $200-500$ \\
\hline Corrected calcium (mmol/L) & $2.24-2.74$ & $2.19-2.69$ & $2.19-2.69$ & $2.15-2.55$ \\
\hline Phosphate $(\mathrm{mmol} / \mathrm{L})$ & $1.10-1.95$ & $1.05-1.75$ & $1.05-1.75$ & $1.05-1.75$ \\
\hline Parathyroid hormone (individual centre) & \multicolumn{4}{|c|}{$\begin{array}{l}\text { Within twice the normal range } \\
\text { Levels may be maintained within normal range if growing appropriately }\end{array}$} \\
\hline Bicarbonate $(\mathrm{mmol} / \mathrm{L})$ & \multicolumn{4}{|c|}{ Reported as either within or outside centre reference range } \\
\hline
\end{tabular}

NICE - National Institute for Health and Care Excellence

\section{Cardiovascular risk factors}

Last year we presented a new cross-sectional evaluation of the prevalence of traditional risk factors for cardiovascular disease, including hypertension, overweight/obesity and hypercholesterolaemia in children with established renal failure (ERF). In this initial analysis, we showed the prevalence of one or more CVRFs in children with ERF in the UK. Evidence for the use of total cholesterol and the relationship of childhood CVRFs with adult CVRFs is available from The National Heart Lung and Blood Institute [6].

\section{Statistical analyses}

Annual and quarterly clinical and laboratory data have been analysed separately, with annual data being used unless stated otherwise. Data were analysed to calculate summary statistics (maximum, minimum, mean and median values in addition to standard deviation and quartile ranges). Where applicable, the percentage achieving the audit standard was also calculated. If a patient had missing data, they were excluded from the relevant analyses.

Longitudinal analyses of attainment of standards were also performed. These were based on a single data point per ERF patient per year collected as described previously. Caution should be exercised in the interpretation of analyses based on data items from a single annual measurement per patient. This is due to changing audit standards over time and variable data returns for previous years. Furthermore, for biochemical variables there are not only differences between assays used at different centres, but also differences in the timing of the result between modalities to take into account. All analyses were performed using SAS 9.3.

\section{Results}

\section{Data completeness}

\section{Annual data}

Tables 10.2 and 10.3 show the completeness of annual data returns for transplant and dialysis patients for 2014 .
Overall, completeness was excellent for key variables in both groups, with the larger group of transplant patients having slightly better completeness for height, BMI, SBP and cholesterol and the smaller group of dialysis patients having somewhat better completeness for PTH, calcium and phosphate. Ferritin completeness is relatively low in transplant patients which may reflect satisfactory graft function and anaemia control, or use of alternative methods of assessing iron stores. Reporting of therapy for anaemia remains patchy and only half the patients have a cholesterol value reported to the paediatric UKRR.

\section{Quarterly data}

Ten centres supplied quarterly 2014 data to the UKRR. Completeness of this data is shown for transplant patients in table 10.4 and dialysis patients in table 10.5. For transplant patients, ferritin and PTH were included in quarterly returns but not widely used; the overall quarterly completeness for ferritin in transplant patients was $40 \%$, and for PTH was $46 \%$.

\section{Growth}

Height

Figures 10.1 and 10.2 show that children receiving RRT were short for their age and sex; those on dialysis were significantly shorter than those with renal transplants. The overall median $z$-score was -1.3 in the transplanted group and -2.1 in the dialysis group, $p<$ 0.0001 . When taking into account data completeness, some centres with apparently less desirable transplant height $\mathrm{z}$-scores had only $54 \%$ completeness. Belfast was excluded from figure 10.2 as no height data for dialysis patients was reported. Figure 10.3 demonstrates that by 
Table 10.2. Percentage data completeness for transplant patients $<18$ years old old by centre for each variable and total number of patients per centre in 2014

\begin{tabular}{|c|c|c|c|c|c|c|c|c|c|c|c|c|c|c|c|}
\hline Centre & $\begin{array}{c}\text { Transplant } \\
\text { patients } \\
N\end{array}$ & Height & Weight & BMI & SBP & $\mathrm{Hb}$ & Creat & Ferr & ESA & $\begin{array}{l}\text { IV } \\
\text { Iron }\end{array}$ & Chol & Bicarb & PTH & $\mathrm{Ca}$ & Phos \\
\hline nam_P & 79 & 91.1 & 91.1 & 91.1 & 91.1 & 91.1 & 91.1 & 41.8 & 0.0 & 0.0 & 0.0 & 91.1 & 82.3 & 91.1 & 91.1 \\
\hline Blfst_P* & 24 & 54.2 & 87.5 & 54.2 & 50.0 & 100.0 & 100.0 & 75.0 & 91.7 & 8.3 & 58.3 & 100.0 & 41.7 & 100.0 & 100.0 \\
\hline Brstl_P* & 43 & 97.7 & 95.4 & 93.0 & 95.4 & 100.0 & 100.0 & 62.8 & 97.7 & 2.3 & 53.5 & 100.0 & 72.1 & 100.0 & 100.0 \\
\hline Cardf_P & 22 & 95.5 & 100.0 & 95.5 & 100.0 & 100.0 & 100.0 & 100.0 & 100.0 & 100.0 & 100.0 & 100.0 & 100.0 & 100.0 & 100.0 \\
\hline Glasg_P* & 44 & 100.0 & 100.0 & 100.0 & 100.0 & 90.9 & 100.0 & 61.4 & 100.0 & 100.0 & 47.7 & 88.6 & 86.4 & 88.6 & 93.2 \\
\hline L Eve_P* & 79 & 98.7 & 98.7 & 98.7 & 98.7 & 98.7 & 98.7 & 98.7 & 94.9 & 98.7 & 93.7 & 98.7 & 98.7 & 98.7 & 98.7 \\
\hline L GOSH_P* & 157 & 94.9 & 96.2 & 94.3 & 94.3 & 96.8 & 96.8 & 96.2 & 22.9 & 20.4 & 33.1 & 96.8 & 96.8 & 96.8 & 96.8 \\
\hline Leeds_P*̄ & 69 & 78.3 & 95.7 & 78.3 & 91.3 & 95.7 & 95.7 & 73.9 & 98.6 & 98.6 & 89.9 & 95.7 & 72.5 & 95.7 & 92.8 \\
\hline Livpl_P & 36 & 88.9 & 88.9 & 88.9 & 88.9 & 88.9 & 86.1 & 83.3 & 88.9 & 86.1 & 69.4 & 86.1 & 2.8 & 88.9 & 86.1 \\
\hline Manch_P* & 52 & 100.0 & 100.0 & 100.0 & 100.0 & 100.0 & 100.0 & 69.2 & 100.0 & 100.0 & 13.5 & 100.0 & 100.0 & 100.0 & 100.0 \\
\hline Newc_. ${ }^{*}$ & 30 & 100.0 & 100.0 & 100.0 & 100.0 & 100.0 & 100.0 & 86.7 & 100.0 & 100.0 & 70.0 & 96.7 & 76.7 & 96.7 & 96.7 \\
\hline Nottm_P* & 68 & 76.5 & 77.9 & 76.5 & 73.5 & 92.7 & 94.1 & 88.2 & 0.0 & 0.0 & 85.3 & 92.7 & 89.7 & 94.1 & 94.1 \\
\hline Soton_P & 23 & 87.0 & 95.7 & 87.0 & 95.7 & 100.0 & 100.0 & 95.7 & 95.7 & 95.7 & 56.5 & 100.0 & 95.7 & 95.7 & 100.0 \\
\hline UK & 726 & 90.8 & 94.2 & 90.4 & 91.7 & 96.0 & 96.6 & 80.0 & 61.3 & 52.6 & 54.0 & 95.6 & 83.3 & 95.7 & 95.7 \\
\hline
\end{tabular}

BMI - body mass index; SBP - systolic blood pressure; Hb - haemoglobin; Creat - creatinine; Ferr - ferritin; ESA - erythropoietin stimulating agent; IV - intravenous; Chol - cholesterol; Bicarb - bicarbonate; PTH - parathyroid hormone; Ca - calcium; Phos - phosphate

* Denotes centre undertaking paediatric kidney transplantation

the time of RRT start, children were already short for their age and sex with an overall median height z-score of -1.4 (shown by the dotted line) with younger children aged 2-8 most affected. Figure 10.4 shows that although transplanted paediatric patients aged up to 12 years improved their height $\mathrm{z}$-score in the first 5 years of starting RRT, those older than 12 started with a better height z-score which was maintained. In contrast, all dialysis patients had a worsening height $\mathrm{z}$-score over time. This was more pronounced in older children, who were better grown at RRT start. It should be noted that due to changes in modality, groups are not strictly sequential in this analysis, and as most patients received a transplant, there are small numbers of dialysis patients at

Table 10.3. Percentage data completeness for dialysis patients $<18$ years old old by centre for each variable and total number of patients per centre in 2014

\begin{tabular}{|c|c|c|c|c|c|c|c|c|c|c|c|c|c|c|}
\hline Centre & $\begin{array}{c}\text { Dialysis } \\
\text { patients } \\
\quad N\end{array}$ & Height & Weight & BMI & SBP & $\mathrm{Hb}$ & Ferr & ESA & $\begin{array}{c}\text { IV } \\
\text { Iron }\end{array}$ & Chol & Bicarb & PTH & $\mathrm{Ca}$ & Phos \\
\hline Bham_P & 24 & 95.8 & 95.8 & 95.8 & 100.0 & 95.8 & 95.8 & 0.0 & 0.0 & 0.0 & 95.8 & 95.8 & 95.8 & 95.8 \\
\hline Blfst_P & 6 & 0.0 & 50.0 & 0.0 & 16.7 & 100.0 & 83.3 & 66.7 & 16.7 & 66.7 & 100.0 & 100.0 & 100.0 & 100.0 \\
\hline Brstl_P & 14 & 100.0 & 100.0 & 100.0 & 100.0 & 100.0 & 100.0 & 100.0 & 100.0 & 78.6 & 100.0 & 92.9 & 100.0 & 100.0 \\
\hline Cardf_P & 6 & 83.3 & 100.0 & 83.3 & 100.0 & 100.0 & 100.0 & 100.0 & 100.0 & 66.7 & 100.0 & 100.0 & 100.0 & 100.0 \\
\hline Glasg_P & 12 & 100.0 & 100.0 & 100.0 & 100.0 & 100.0 & 100.0 & 100.0 & 100.0 & 58.3 & 91.7 & 100.0 & 100.0 & 100.0 \\
\hline L Eve_P & 20 & 90.0 & 100.0 & 90.0 & 100.0 & 100.0 & 100.0 & 90.0 & 100.0 & 60.0 & 100.0 & 100.0 & 100.0 & 100.0 \\
\hline L GOSH_P & 28 & 96.4 & 100.0 & 96.4 & 96.4 & 100.0 & 82.1 & 100.0 & 100.0 & 64.3 & 100.0 & 100.0 & 100.0 & 100.0 \\
\hline Leeds_P & 17 & 76.5 & 100.0 & 76.5 & 88.2 & 100.0 & 100.0 & 100.0 & 100.0 & 76.5 & 100.0 & 100.0 & 100.0 & 100.0 \\
\hline Livpl_P & 5 & 60.0 & 80.0 & 60.0 & 80.0 & 80.0 & 80.0 & 80.0 & 60.0 & 60.0 & 60.0 & 80.0 & 80.0 & 80.0 \\
\hline Manch_P & 33 & 90.9 & 97.0 & 90.9 & 93.9 & 97.0 & 97.0 & 100.0 & 97.0 & 15.2 & 100.0 & 97.0 & 100.0 & 100.0 \\
\hline Newc_P & 7 & 100.0 & 100.0 & 100.0 & 100.0 & 85.7 & 85.7 & 100.0 & 100.0 & 57.1 & 85.7 & 85.7 & 85.7 & 85.7 \\
\hline Nottm_P & 17 & 52.9 & 58.8 & 52.9 & 29.4 & 100.0 & 94.1 & 0.0 & 0.0 & 52.9 & 100.0 & 94.1 & 100.0 & 100.0 \\
\hline Soton_P & 2 & 100.0 & 100.0 & 100.0 & 100.0 & 100.0 & 100.0 & 100.0 & 100.0 & 50.0 & 100.0 & 50.0 & 100.0 & 100.0 \\
\hline UK & 191 & 85.3 & 93.2 & 85.3 & 88.0 & 97.9 & 94.2 & 75.9 & 74.4 & 47.6 & 97.4 & 96.3 & 98.4 & 98.4 \\
\hline
\end{tabular}

BMI - body mass index; SBP - systolic blood pressure; Hb - haemoglobin; Ferr - ferritin; ESA - erythropoietin stimulating agent; IV intravenous; Chol - cholesterol; Bicarb - bicarbonate; PTH - parathyroid hormone; Ca - calcium; Phos - phosphate 
Table 10.4. Percentage data completeness for transplant patients $<18$ years old old by centre reporting quarterly laboratory data

\begin{tabular}{|c|c|c|c|c|c|c|}
\hline \multirow[b]{2}{*}{ Centre } & \multicolumn{6}{|c|}{ Transplant patients } \\
\hline & $N$ & Creatinine & $\mathrm{Hb}$ & Calcium & Phosphate & Bicarbonate \\
\hline Bham_P & 79 & 85.7 & 100.0 & 85.7 & 85.7 & 85.7 \\
\hline Blfst_P & 24 & 100.0 & 95.7 & 100.0 & 100.0 & 100.0 \\
\hline Brstl_P & 43 & 95.2 & 92.0 & 92.7 & 92.1 & 89.7 \\
\hline Cardf_P & 22 & 74.1 & 72.7 & 74.1 & 74.1 & 74.1 \\
\hline Glasg_P & 44 & 71.5 & 84.3 & 71.5 & 71.5 & 88.6 \\
\hline L Eve_P & 79 & 98.0 & 98.7 & 98.0 & 98.0 & 98.0 \\
\hline L GOSH_P & 157 & 98.0 & 99.1 & 97.8 & 97.4 & 97.3 \\
\hline Leeds_P & 69 & 90.7 & 100.0 & 90.3 & 88.3 & 89.1 \\
\hline Newc_P & 30 & 85.1 & 93.8 & 85.1 & 85.1 & 71.1 \\
\hline Nottm_P & 68 & 87.9 & 92.9 & 87.9 & 87.9 & 87.4 \\
\hline Overall & 615 & 88.6 & 92.9 & 88.3 & 88.0 & 88.1 \\
\hline
\end{tabular}

Table 10.5. Percentage data completeness for dialysis patients $<18$ years old old by centre reporting quarterly laboratory data

\begin{tabular}{|c|c|c|c|c|c|c|c|}
\hline \multirow[b]{2}{*}{ Centre } & \multicolumn{7}{|c|}{ Dialysis patients } \\
\hline & $N$ & $\mathrm{Hb}$ & Ferritin & Calcium & Phosphate & PTH & Bicarbonate \\
\hline Bham_P & 24 & 100.0 & 75.8 & 100.0 & 100.0 & 100.0 & 100.0 \\
\hline Blfst_P & 6 & 95.7 & 91.3 & 95.7 & 95.7 & 95.7 & 95.7 \\
\hline Brstl_P & 14 & 92.0 & 84.0 & 92.0 & 92.0 & 92.0 & 92.0 \\
\hline Cardf_P & 6 & 72.7 & 72.7 & 72.7 & 72.7 & 63.6 & 72.7 \\
\hline Glasg_P & 12 & 84.3 & 78.4 & 84.3 & 84.3 & 80.4 & 91.7 \\
\hline L Eve_P & 20 & 98.7 & 94.7 & 98.7 & 98.7 & 96.1 & 98.7 \\
\hline L GOSH_P & 28 & 99.1 & 40.5 & 99.1 & 99.1 & 98.3 & 99.1 \\
\hline Leeds_P & 17 & 100.0 & 92.4 & 100.0 & 100.0 & 89.4 & 100.0 \\
\hline Newc_P & 7 & 93.8 & 93.8 & 87.5 & 93.8 & 87.5 & 93.8 \\
\hline Nottm_P & 17 & 92.9 & 92.9 & 94.3 & 94.3 & 92.9 & 94.3 \\
\hline Overall & 151 & 92.9 & 81.7 & 92.4 & 93.1 & 89.6 & 93.8 \\
\hline
\end{tabular}

$\mathrm{Hb}$ - haemoglobin; PTH - parathyroid hormone

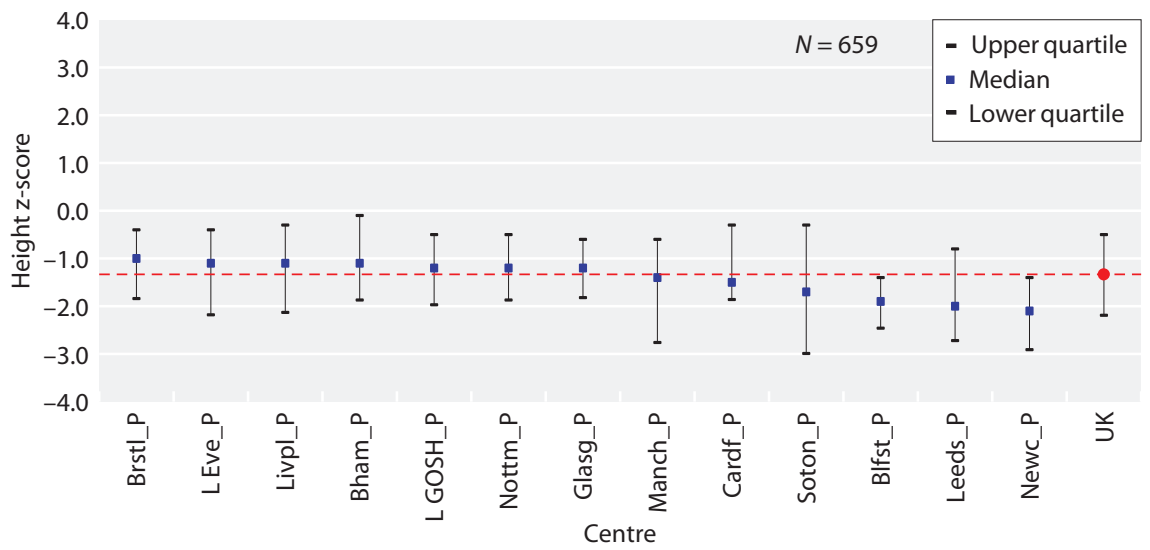

Fig. 10.1. Median height $\mathrm{z}$-scores for transplant patients $<18$ years old in 2014 , centre specific and national averages

five years after starting RRT. Data for 16-18 year olds was omitted owing to small group numbers.

The proportion of patients aged 2-18 years with a height less than two standard deviations in 2014 was much higher for those on dialysis (55.9\% for haemodialysis (HD) and
43.6\% for peritoneal dialysis (PD)) compared to those with a functioning transplant (26.0\%), excluding situations where growth might be compromised, for example patients with syndromes and those born prematurely. For transplanted patients, the proportion increased with age, with 

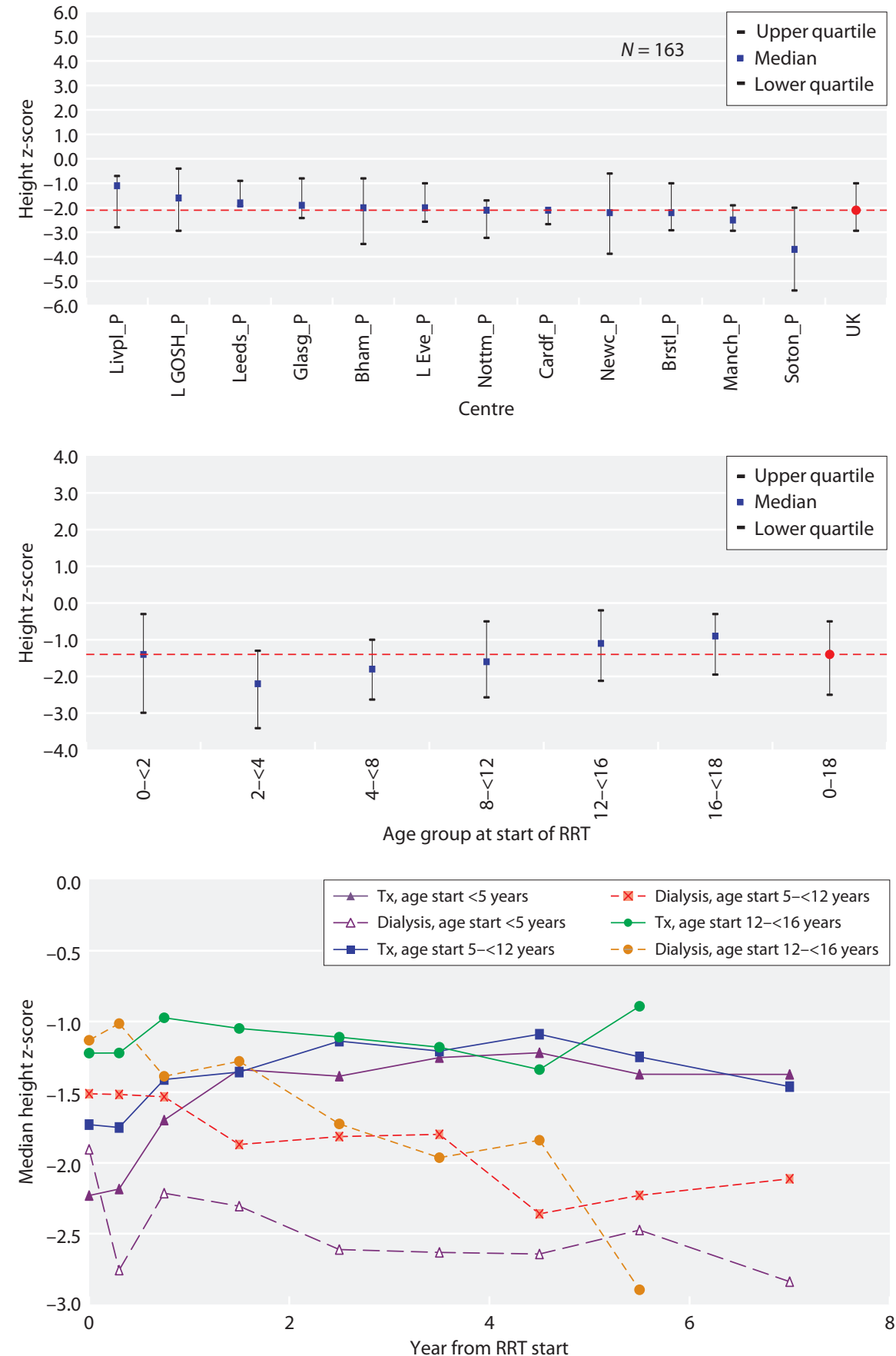

Fig. 10.2. Median height $\mathrm{z}$-scores for dialysis patients $<18$ years old in 2014 , centre specific and national averages

Fig. 10.3. Median height $\mathrm{z}$-scores at start of RRT for patients $<18$ years old between 2003 and 2014, by age at start

Fig. 10.4. Median height $z$-scores for patients $<16$ years old by time on RRT and treatment modality
$20.5 \%$ of those aged $5-<12$ having a height $\mathrm{z}$-score less than two standard deviations, $26.3 \%$ of those aged 12 $<16$ and $32.2 \%$ of those aged $16-<18$. No comments can be made at centre level or for dialysis patients due to small patient numbers. Figure 10.5 shows large variation in the use of growth hormone in those with a height less than two standard deviations. The proportion of patients with a height less than two standard deviations whose growth hormone status was not known is high (ranging from approximately $10 \%$ in 2010 to $50 \%$ in 2011 ), and this limits meaningful interpretation. Average use of growth hormone for patients aged under 18 with a height less than two standard deviations since 2003 is $26.1 \%$ for dialysis patients and $10.2 \%$ for transplant patients.

\section{Weight}

Figures 10.6 and 10.7 show that paediatric patients receiving dialysis were significantly more underweight 

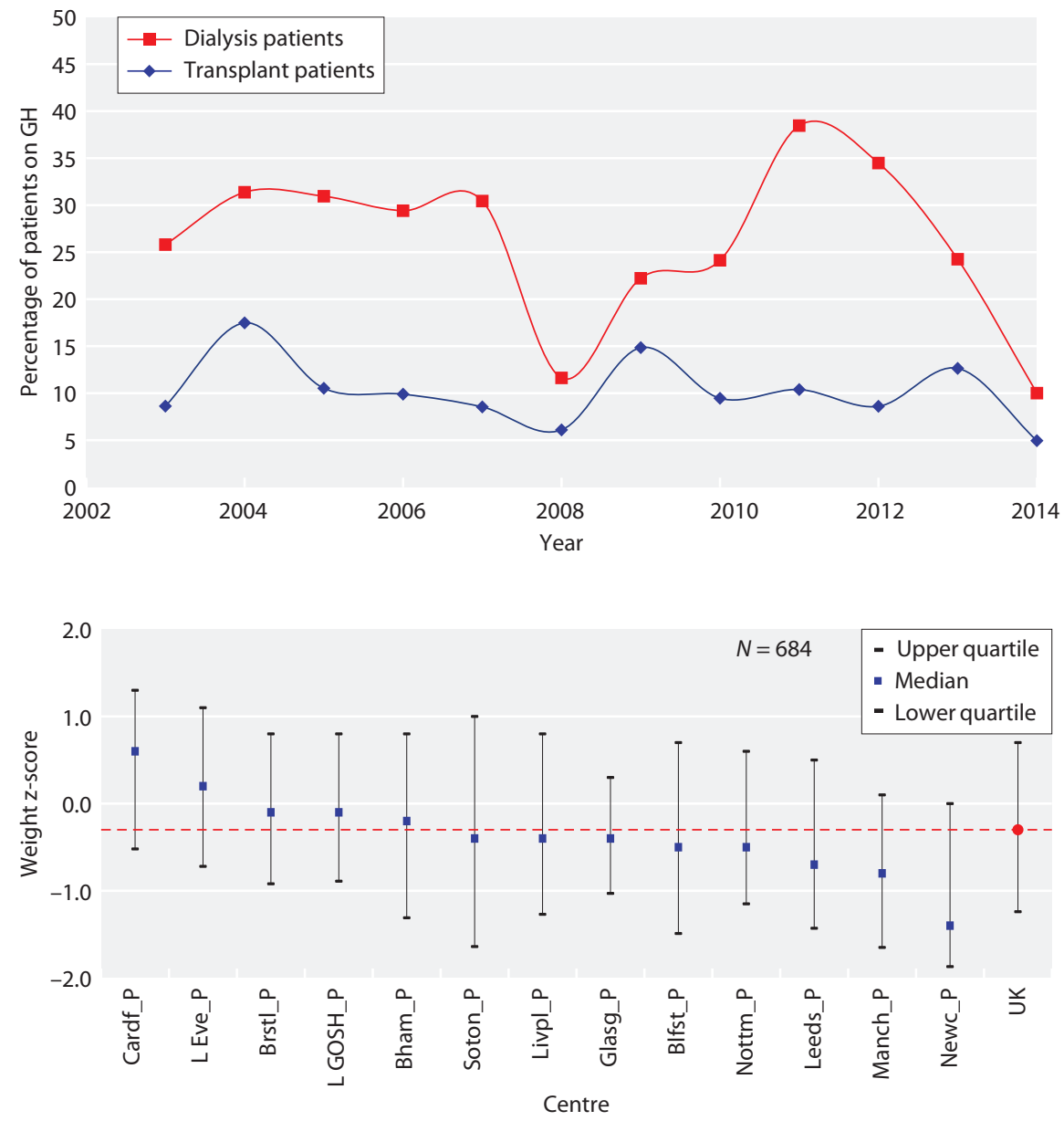

Fig. 10.5. Use of growth hormone in children $<18$ years old with a height under 2SD between 2003 and 2014
Fig. 10.6. Median weight $\mathrm{z}$-scores for transplant patients $<18$ years old in 2014, centre specific and national averages

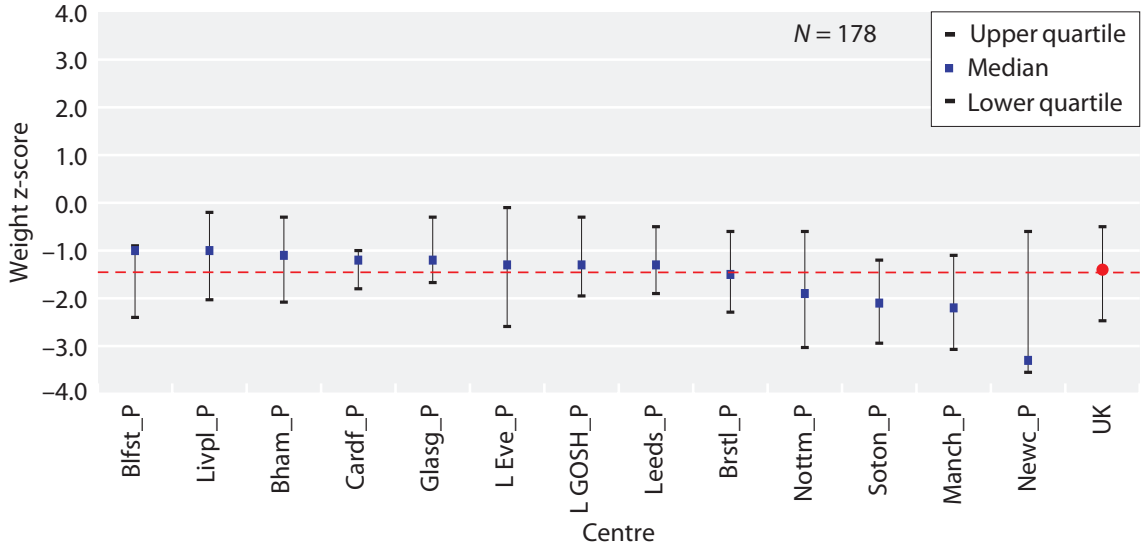

Fig. 10.7. Median weight z-scores for dialysis patients $<18$ years old in 2014, centre specific and national averages for age and sex than those with renal transplants. The overall median $\mathrm{z}$-score was -0.3 in the transplanted group and -1.4 in the dialysis group, $p<0.0001$. Centre level comparison for dialysis patients in particular should be avoided due to low numbers per centre.

When taking height into account and examining BMI rather than weight alone, figures 10.8 and 10.9 show that BMI z-scores are mostly within the upper half of the normal range for transplant patients, and spread throughout the normal range in dialysis patients. The majority of paediatric RRT patients have a BMI within the normal range, as shown in figure 10.10 . 


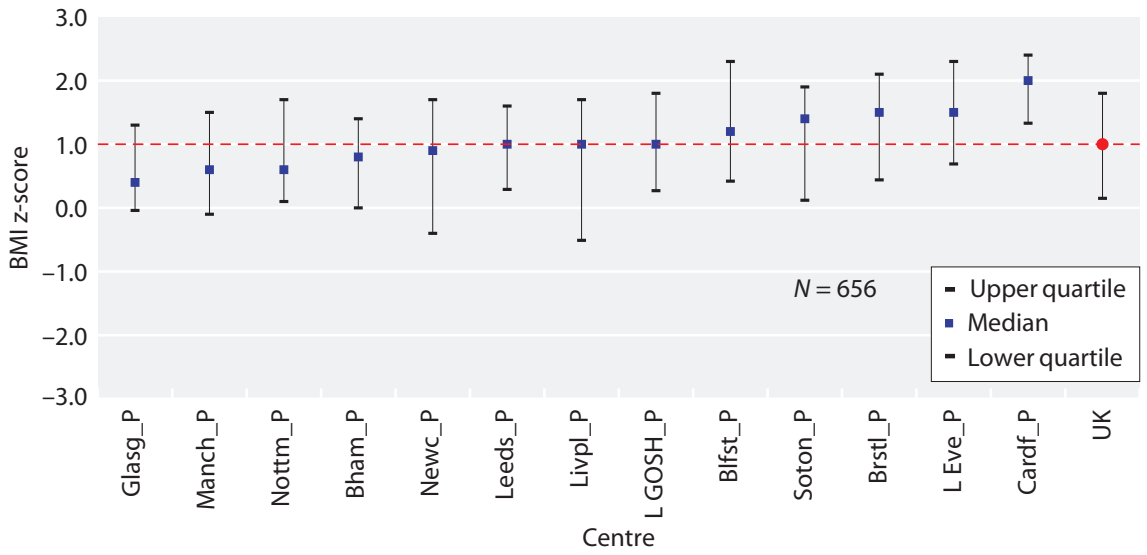

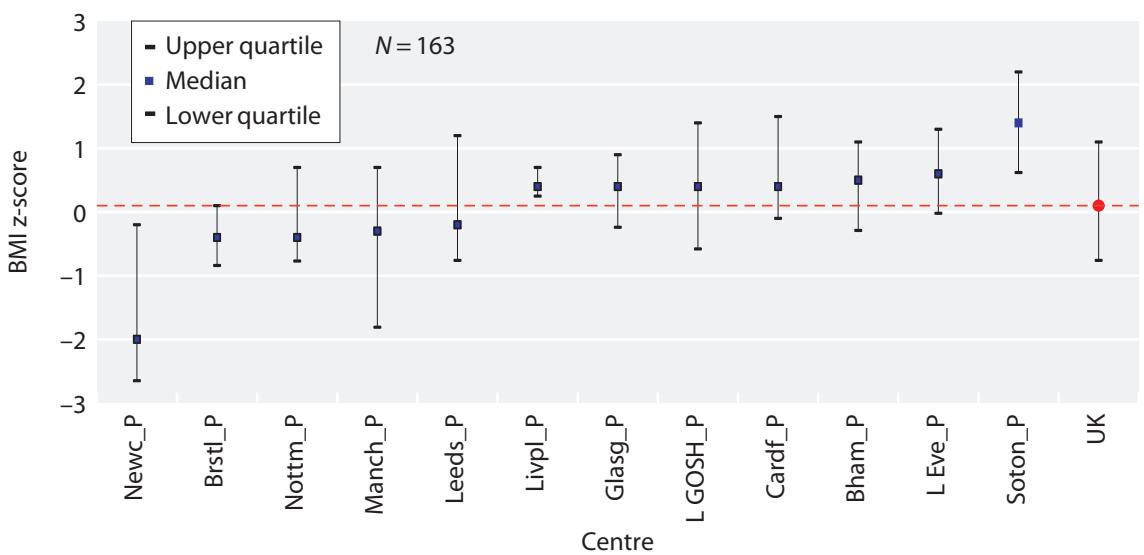

Fig. 10.8. Median BMI z-scores for transplant patients $<18$ years old in 2014, centre specific and national averages

Fig. 10.9. Median BMI z-scores for dialysis patients $<18$ years old in 2014, centre specific and national averages

\section{Cardiovascular risk factor evaluation Obesity}

Figures 10.8 and 10.9 show that children with renal transplants had a significantly higher body mass index for age and sex than those receiving dialysis. The overall median $\mathrm{z}$-score was 1.0 in the transplanted group and 0.1 in the dialysis group, $p<0.0001$.

Figure 10.10 demonstrates higher proportions of overweight and obese children in those with renal transplants

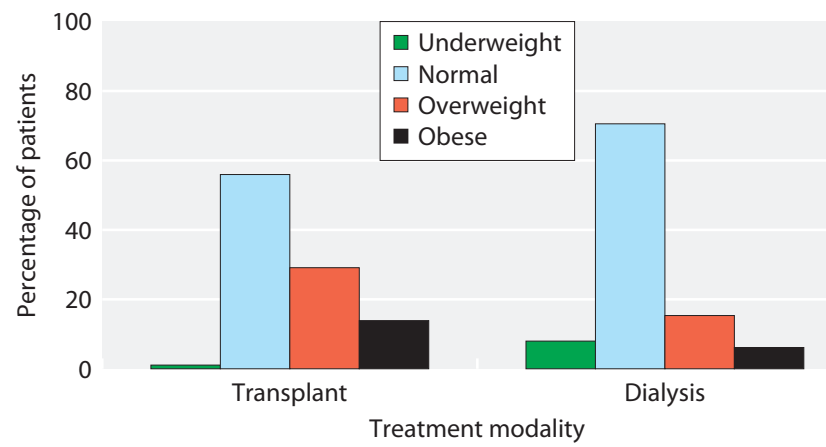

Fig. 10.10. BMI categorisation in children $<18$ years old by modality in 2014
(43.0\%) compared to those receiving dialysis (21.5\%). There was a higher proportion of underweight children in the dialysis group (8.0\%) compared to those with renal transplants $(1.1 \%)$.

Of those aged 16 to $<18$ years, $44.4 \%$ were overweight or obese compared to $23.7 \%$ of those aged 0 to $<5$ years, but there was no significant difference by age in the transplant patient group. There were no statistically significant differences between proportions of those underweight, normal, overweight or obese in terms of sex, ethnicity or donor source (deceased or living).

\section{Hypertension}

Figures 10.11 and 10.12 show paediatric patients receiving RRT were hypertensive compared to the healthy population, and those receiving dialysis had a significantly higher median SBP than those with renal transplants. There was wide inter-centre variability in median SBP $\mathrm{z}$-score, with many centres having wide confidence intervals that included zero. The median SBP z-score was maintained at or below the 90th percentile by all but one centre for those with transplants whereas four centres 

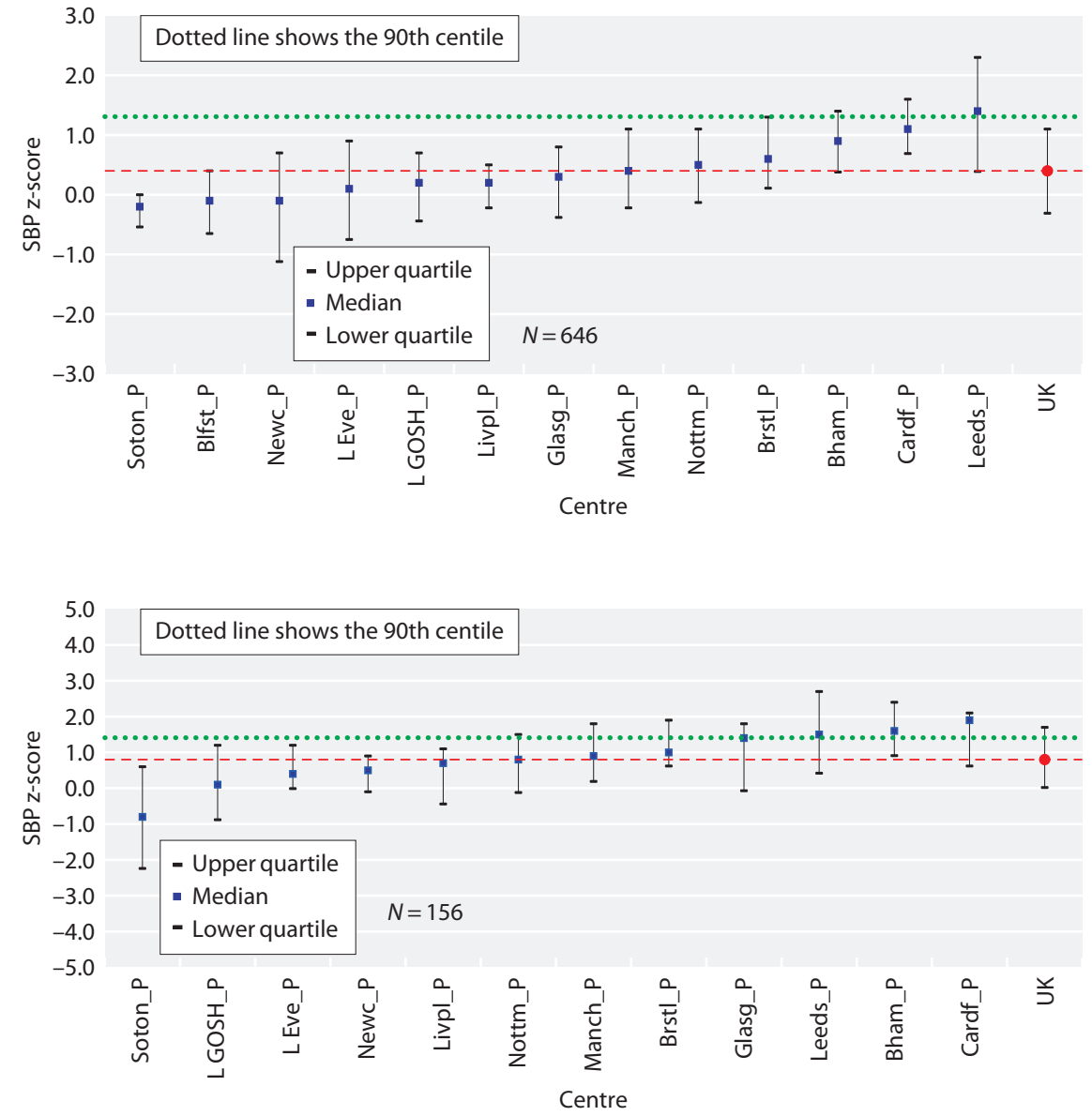

Fig. 10.11. Median systolic blood pressure $\mathrm{z}$-scores for transplant patients $<18$ years old in 2014, centre specific and national averages

Fig. 10.12. Median systolic blood pressure $\mathrm{Z}$-scores for dialysis patients $<18$ years old in 2014 , centre specific and national averages

were above the 90th percentile for median SBP z-score for those receiving dialysis. The overall median $\mathrm{z}$-score was 0.4 in the transplanted group and 0.8 in the dialysis group, $p<0.0001$. Of those aged $<18,80.2 \%$ of children with a functioning kidney transplant, $57.3 \%$ of those receiving $\mathrm{HD}$, and $70.3 \%$ of those receiving $\mathrm{PD}$ had a SBP < 90th percentile in 2014. No comments can be made at centre level or for dialysis patients due to small patient numbers. Table 10.6 shows that there were significant differences in the percentage below the 90th percentile for SBP between RRT modalities, gender, and ethnicity. There was no statistically significant difference in SBP between age groups, HD and PD or between living and deceased donor transplants.

Cardiovascular risk factor prevalence

Table 10.7 shows that the percentage of patients with no CVRFs was $22.7 \%$, one CVRF was $39.3 \%$, two CVRFs was $27.8 \%$ and the percentage of those with all evaluated CVRFs was $10.3 \%$. This analysis is restricted to the 428 of 917 (46.7\%) patients with complete data for all three items. Thus of the included prevalent
Table 10.6. Percentage of patients $<18$ years old achieving the standard for systolic blood pressure in 2014

\begin{tabular}{lrcc} 
& & $\begin{array}{c}\text { \% below } \\
\text { 90th percentile }\end{array}$ & $p$ value \\
\hline Total & $N 02$ & 76.9 & \\
Age group (years) & & & 0.07 \\
$0-<5$ & 91 & 71.4 & \\
$5-<12$ & 310 & 73.6 & \\
$12-<16$ & 257 & 81.3 & \\
$16-<18$ & 144 & 79.9 & 0.0002 \\
Gender & & & \\
Male & 501 & 81.2 & 0.007 \\
Female & 301 & 69.8 & \\
Ethnicity & & & \\
Black & 32 & 78.1 & \\
Other & 54 & 75.9 & \\
South Asian & 137 & 65.7 & \\
White & 571 & 79.7 & \\
RRT modality & & & \\
Dialysis & 156 & 63.5 & \\
Transplant & 646 & 80.2 & \\
\hline & & & \\
\hline
\end{tabular}


Table 10.7. Frequency of number of cardiovascular risk factors in prevalent RRT patients <18 years old in 2014

\begin{tabular}{|c|c|c|c|c|c|c|}
\hline Number of CV risk factors & Hypertensive & OW/Obese & Hypercholesterolaemic & $N$ & $\%$ & Total \% \\
\hline 0 & No & No & No & 97 & 22.7 & 22.7 \\
\hline \multirow{2}{*}{1} & No & Yes & No & 60 & 14.0 & 39.3 \\
\hline & No & No & Yes & 60 & 14.0 & \\
\hline 2 & Yes & Yes & No & 37 & 8.6 & \\
\hline 3 & Yes & Yes & Yes & 44 & 10.3 & 10.3 \\
\hline$N$ & 163 & 189 & 186 & & & \\
\hline Total \% & 38.1 & 44.2 & 43.5 & & & \\
\hline
\end{tabular}

$\mathrm{CV}$ - cardiovascular; OW - overweight

paediatric RRT population three quarters had one or more risk factors for cardiovascular disease, with 1 in 10 having all three risk factors evaluated. Of those included in this analysis, 163 (38.1\%) had hypertension, 189 (44.2\%) were overweight/obese and 186 (43.5\%) had hypercholesterolaemia. There were no statistically significant differences in number of CVRFs according to age, gender, ethnicity or modality.

\section{Laboratory and clinical indices - quarterly data}

Tables 10.8 and 10.10 display the median values and interquartile ranges (IQR) for quarterly laboratory parameters for paediatric transplant and dialysis patients in 2014 by centre, with table 10.9 showing age specific creatinine results. The total number of data points for each parameter varied depending on completeness, ranging from 2,059 data points for creatinine in transplant patients to 430 data points for ferritin in dialysis patients.

For transplant patients, these results demonstrate excellent average graft function in the paediatric population, with associated good anaemia control and normal bone metabolism markers. The overall median ferritin in transplant patients was 61 (IQR 32-139) $\mu \mathrm{g} / \mathrm{L}$ based on $40 \%$ completeness. Similarly the overall median PTH in transplant patients was 5.9 (IQR 3.9-8.9) pmol/L based on $46 \%$ completeness, again likely to be unused in the absence of transplant related chronic kidney disease.

For dialysis patients, the average haemoglobin and ferritin were in target. For bone biochemistry, although average calcium and phosphate were in range, there was evidence of hyperparathyroidism with average PTH

Table 10.8. Median quarterly laboratory data by centre in prevalent transplant patients $<18$ years old in 2014

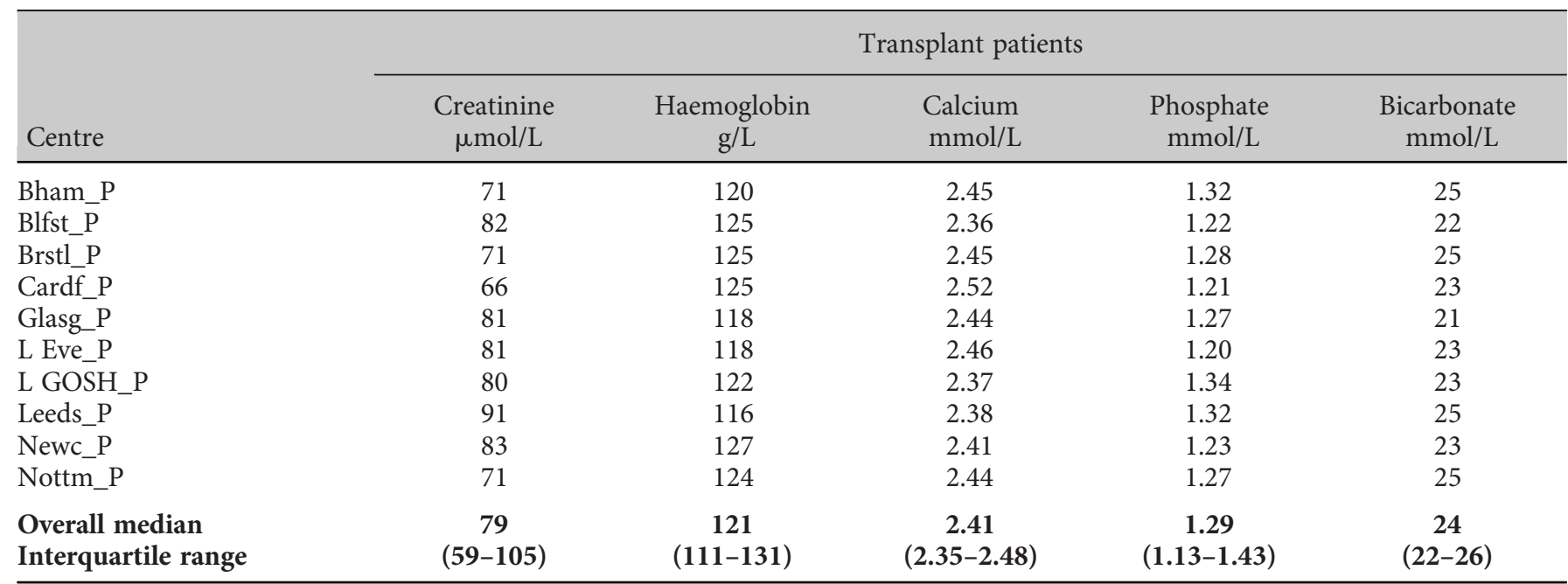


Table 10.9. Median quarterly creatinine by age group and centre in prevalent transplant patients $<18$ years old in 2014

\begin{tabular}{|c|c|c|c|c|c|c|c|c|}
\hline \multirow[b]{3}{*}{ Centre } & \multicolumn{8}{|c|}{ Age group } \\
\hline & \multicolumn{2}{|c|}{$0-<5$} & \multicolumn{2}{|c|}{$5-<12$} & \multicolumn{2}{|c|}{$12-<16$} & \multicolumn{2}{|c|}{$16-<18$} \\
\hline & $N$ & $\begin{array}{l}\text { Creatinine } \\
\text { umol/L }\end{array}$ & $N$ & $\begin{array}{l}\text { Creatinine } \\
\text { umol/L }\end{array}$ & $N$ & $\begin{array}{l}\text { Creatinine } \\
\text { umol/L }\end{array}$ & $N$ & $\begin{array}{l}\text { Creatinine } \\
\text { umol/L }\end{array}$ \\
\hline Bham_P & 14 & 41 & 92 & 63 & 95 & 83 & 26 & 94 \\
\hline Blfst_- & 6 & 55 & 52 & 77 & 8 & 64 & 27 & 109 \\
\hline Brstl_P & 7 & 45 & 90 & 60 & 27 & 83 & 33 & 102 \\
\hline Cardf_P & 0 & & 35 & 64 & 16 & 66 & 9 & 85 \\
\hline Glasg_P & 4 & 51 & 39 & 59 & 57 & 94 & 13 & 119 \\
\hline L Eve_P & 22 & 41 & 110 & 74 & 95 & 99 & 61 & 96 \\
\hline L GOS̈H_P & 56 & 37 & 228 & 65 & 178 & 97 & 112 & 120 \\
\hline Leeds_P & 10 & 42 & 76 & 80 & 96 & 97 & 51 & 99 \\
\hline Newc_P & 4 & 34 & 13 & 41 & 40 & 83 & 40 & 100 \\
\hline Nottm_P & 11 & 32 & 98 & 67 & 77 & 74 & 31 & 99 \\
\hline $\begin{array}{l}\text { Total } N \text { and overall UK median } \\
\text { Interquartile range }\end{array}$ & 134 & $\begin{array}{c}40 \\
(33-49)\end{array}$ & 833 & $\begin{array}{c}66 \\
(52-85)\end{array}$ & 689 & $\begin{array}{c}89 \\
(71-114)\end{array}$ & 403 & $\begin{array}{c}104 \\
(85-131)\end{array}$ \\
\hline
\end{tabular}

Blank cell denotes missing data

over target at more than twice the upper limit of normal, with variation between centres. Control of acidosis was also within the desired range.

\section{Laboratory and clinical indices - annual data \\ Haemoglobin and ferritin}

The percentage of patients aged $<18$ on dialysis achieving the haemoglobin standard in 2014 was $61.8 \%$ for those on HD and 76.5\% for those on PD, compared to $92.5 \%$ for those with a renal transplant. There was no pattern by age, and no comments could be made at centre level or for dialysis patients due to small patient numbers. During 2012-2014, 74.6\% of dialysis patients and $92.2 \%$ of transplant patients achieved the standard for haemoglobin, which has remained consistent since the 2003-2005 period. The proportion of patients with a ferritin in range during 2012-2014 was 35.5\% for dialysis patients and $14.5 \%$ for transplant patients. It is not possible to draw conclusions on ferritin data trends, as the completeness for transplant patients was only $40.6 \%$ in the $2003-2005$ period, but had improved to $77.5 \%$ in the $2012-2014$ period. A similar improvement

Table 10.10. Median quarterly laboratory data by centre in prevalent dialysis patients $<18$ years old in 2014

\begin{tabular}{|c|c|c|c|c|c|c|}
\hline \multirow[b]{2}{*}{ Centre } & \multicolumn{6}{|c|}{ Dialysis patients } \\
\hline & $\begin{array}{l}\text { Haemoglobin } \\
\text { g/L }\end{array}$ & $\begin{array}{c}\text { Ferritin } \\
\mu \mathrm{g} / \mathrm{L}\end{array}$ & $\begin{array}{l}\text { Calcium } \\
\mathrm{mmol} / \mathrm{L}\end{array}$ & $\begin{array}{c}\text { Phosphate } \\
\text { mmol/L }\end{array}$ & $\begin{array}{c}\mathrm{PTH} \\
\mathrm{pmol} / \mathrm{L}\end{array}$ & $\begin{array}{c}\text { Bicarbonate } \\
\mathrm{mmol} / \mathrm{L}\end{array}$ \\
\hline Bham_P & 112 & 245 & 2.57 & 1.65 & 14.5 & 26 \\
\hline Blfst_P & 117 & 1,117 & 2.46 & 1.03 & 21.8 & 27 \\
\hline Brstl_P & 111 & 453 & 2.60 & 1.36 & 5.1 & 24 \\
\hline Cardf_P & 114 & 316 & 2.61 & 1.36 & 44.2 & 22 \\
\hline Glasg_P & 106 & 146 & 2.46 & 1.18 & 17.6 & 20 \\
\hline L Eve_P & 108 & 334 & 2.48 & 1.50 & 31.1 & 24 \\
\hline L GOSH_P & 117 & 203 & 2.47 & 1.39 & 9.0 & 25 \\
\hline Leeds_P & 101 & 330 & 2.46 & 2.07 & 42.5 & 26 \\
\hline Newc_P & 102 & 319 & 2.54 & 1.23 & 9.2 & 24 \\
\hline Nottm_P & 103 & 229 & 2.50 & 1.21 & 21.8 & 30 \\
\hline Overall median & 109 & 280 & 2.50 & 1.48 & 17.3 & 26 \\
\hline Interquartile range & $(98-121)$ & $(137-492)$ & $(2.41-2.61)$ & $(1.10-1.88)$ & $(6.9-46.0)$ & $(23-29)$ \\
\hline
\end{tabular}

PTH - parathyroid hormone 
Table 10.11. Proportion of paediatric RRT patients on ESA, by haemoglobin attainment, across time

\begin{tabular}{lcc}
\hline Time period & $\begin{array}{c}\text { Hb below standard } \\
\text { \% on ESA }\end{array}$ & $\begin{array}{c}\text { Hb above standard } \\
\% \text { on ESA }\end{array}$ \\
\hline Transplant patients & & \\
2003-2005 & 20.2 & 3.8 \\
2006-2008 & 22.9 & 4.6 \\
2009-2011 & 22.2 & 6.9 \\
2012-2014 & 26.0 & 4.3 \\
Dialysis patients & & \\
2003-2005 & 96.6 & 92.3 \\
2006-2008 & 94.9 & 95.7 \\
2009-2011 & 88.1 & 80.7 \\
$2012-2014$ & 85.5 & 90.2 \\
\hline
\end{tabular}

$\mathrm{Hb}$ - haemoglobin; ESA - erythropoietin stimulating agent

was also seen for dialysis ferritin data, increasing from $72.9 \%$ to $94.8 \%$ over the same time periods.

At first inspection, table 10.11 appears to show increasing use of erythropoietin stimulating agents (ESAs) over time in transplant patients and a decrease in use of ESAs in dialysis patients over time. However the amount of missing data increased from $2.5 \%$ in the 2003-2005 period to $22.5 \%$ in the most recent period for dialysis patients, and by a similar margin for the transplant patients.

Overall, figure 10.13 shows high usage of ESAs in dialysis patients without a clear difference by haemoglobin standard, noting erratic results from 2010 when there was a reduction in data completeness. Usage of ESAs in transplant patients remained low and reasonably stable with a more discernible separation by haemoglobin standard. Figure 10.14 is similar to figure 10.13 but demonstrates wider variation for usage of intravenous (IV) iron for dialysis patients by haemoglobin standard, in keeping with low completeness for past years, and low usage of IV iron in transplant patients.

\section{Calcium}

The percentage of patients aged $<18$ on $\operatorname{HD}(n=102)$ achieving the calcium standard in 2014 was $82.4 \%$, with $5.9 \%$ of patients being hypocalcaemic, and $11.8 \%$ being hypercalcaemic. The percentage of patients aged $<18$ on PD $(n=86)$ achieving the calcium standard in 2014 was $72.1 \%$, with no patients being hypocalcaemic, and $27.9 \%$ being hypercalcaemic. Small cohort numbers prevent commentary at centre level or by age group.

\section{Phosphate}

The percentage of patients aged $<18$ on $\mathrm{HD}(n=102)$ achieving the phosphate standard in 2014 was 51.0\%, with $12.8 \%$ of patients being hypophosphataemic, and $36.3 \%$ being hyperphosphataemic. The percentage of patients aged $<18$ on PD $(n=86)$ achieving the phosphate standard in 2014 was $53.5 \%$, with $11.6 \%$ of patients being hypophosphataemic, and $34.9 \%$ being hyperphosphataemic.

Small cohort numbers prevent commentary at centre level or by age group.

\section{Parathyroid hormone}

The percentage of patients aged $<18$ with a renal transplant $(n=605)$ achieving the PTH standard in 2014 was $83.5 \%$, with $16.5 \%$ having hyperparathyroidism. The percentage of patients aged $<18$ on $\mathrm{HD}(n=$ 98) achieving the PTH standard in 2014 was $38.8 \%$, with $61.2 \%$ having hyperparathyroidism. The percentage of patients aged $<18$ on PD $(n=86)$ achieving the PTH standard in 2014 was 32.6\%, with $67.4 \%$ having hyperparathyroidism. Small cohort numbers and low

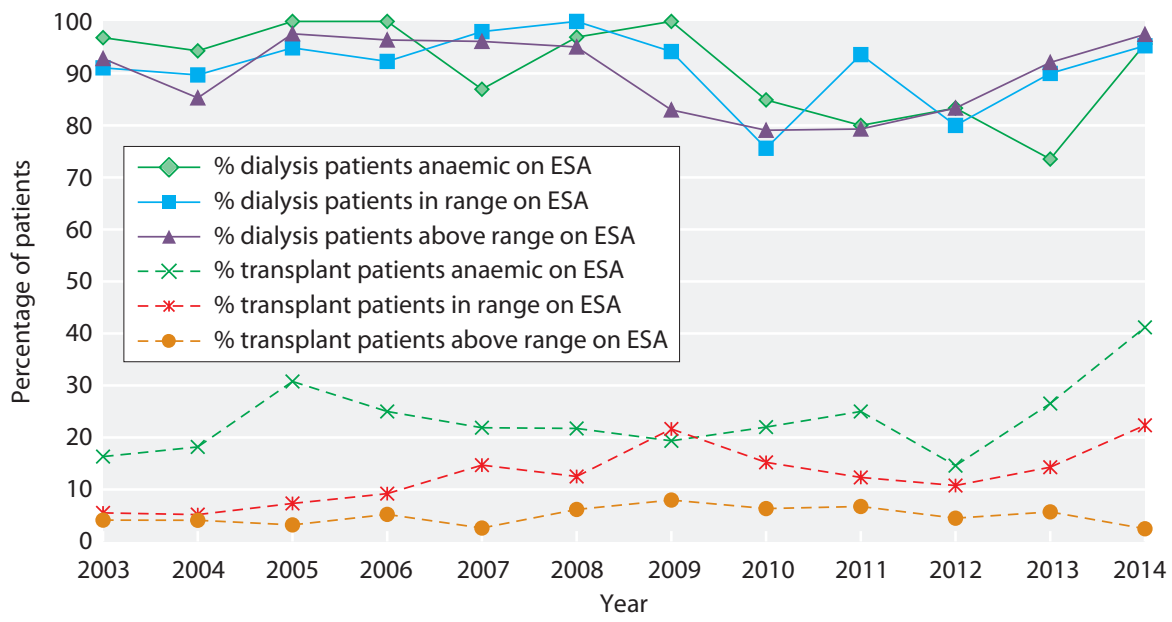

Fig. 10.13. The use of ESA by haemoglobin standard and treatment modality between 2003 and 2014 in prevalent RRT patients $<18$ years old 


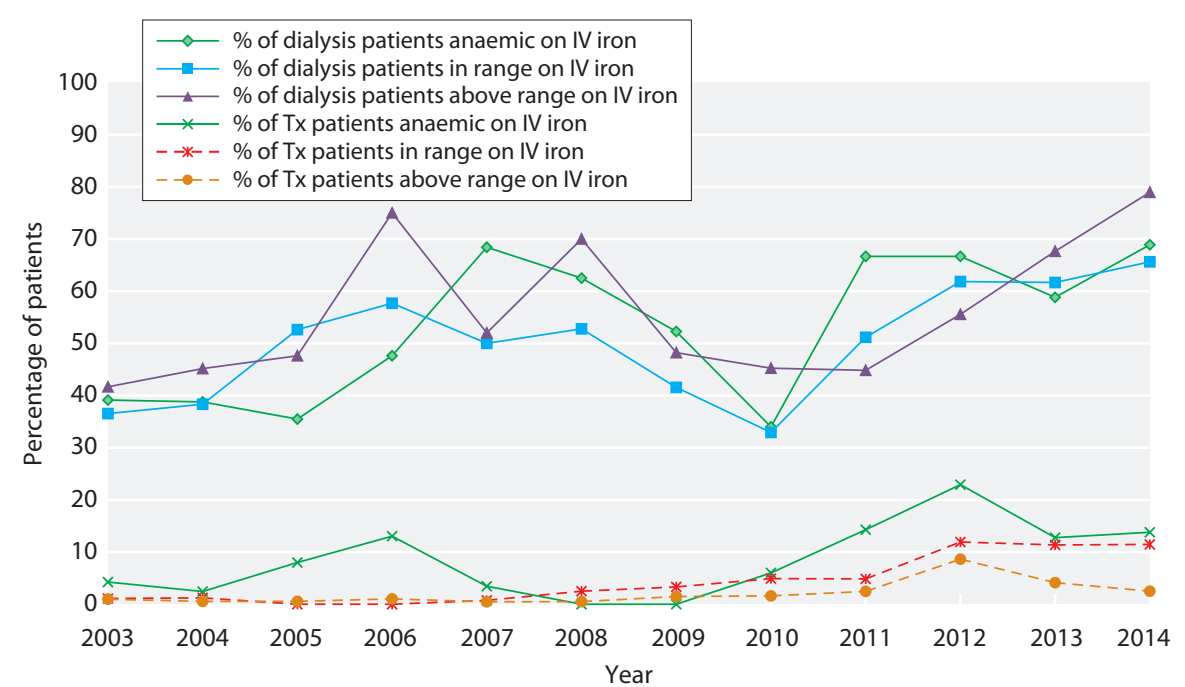

Fig. 10.14. The use of intravenous iron by haemoglobin standard and treatment modality between 2003 and 2014 in prevalent RRT patients $<18$ years old completeness from some centres for transplant patients prevent commentary at centre level or by age group.

\section{Bicarbonate}

The percentage of patients aged $<18$ with a renal transplant $(n=694)$ achieving the bicarbonate standard in 2014 was $85.7 \%$, with $10.4 \%$ being below the standard and $3.9 \%$ being above the standard. The percentage of patients aged $<18$ on HD $(n=100)$ achieving the bicarbonate standard in 2014 was $75.0 \%$, with $18.0 \%$ being below the standard and $7.0 \%$ being above the standard. The percentage of patients aged $<18$ on PD $(n=86)$ achieving the bicarbonate standard in 2014 was $68.6 \%$, with $5.8 \%$ being below the standard and $25.6 \%$ being above the standard.

Small cohort numbers prevent commentary at centre level or by age group.

\section{Discussion}

This chapter provides information describing clinical and laboratory parameters of paediatric RRT patients in the UK. This enables comparison against national standards and guidelines, assessment of quality of care and benchmarking the performance of UK tertiary paediatric nephrology centres. Data from 2014 and trends over the last 12 years have been analysed. The results and conclusions are a valuable resource for the paediatric renal community and this data accounts for nearly $20 \%$ of European Paediatric Renal Registry data.

Major additions this year are (i) a section including quarterly data from 10 of 13 centres; and (ii) data on all patients, including 16-18 year olds reported to the paediatric UKRR.
The efforts of the past few years have continued to improve data quality to enable conclusions to be drawn with greater confidence against a background of small patient numbers from a relatively rare condition. An example of this is seeking to receive quarterly rather than annual data to ensure better representation from centres.

\section{Quarterly data}

Ten centres provided quarterly biochemistry data for analysis. This has enabled the reporting of actual average values for the parameters collected which is a major change providing reassuring evidence of excellent graft function for those with a transplant, and good control of anaemia and acidosis in those on dialysis, perhaps with some room for improvement for metabolic bone disease management. The data presented has good coverage of the UK with only one larger centre and two smaller centres being omitted to date (Southampton did provide quarterly data for height, weight and $\mathrm{BP}$ but not biochemistry).

This progress moves the paediatric and adult renal registry databases a big step closer to unification which would allow more comprehensive reporting, especially of adolescents and young adults who may be managed in paediatric or adult services.

The ongoing challenge is to continue to work with the three remaining centres to achieve quarterly biochemistry returns, and to improve extracts to allow new data to be loaded into a single UKRR database.

\section{Highlights from the 2014 data}

For core items there was very good completeness. Anaemia and growth hormone therapy data continues to be patchy but more complete for dialysis patients. 
Growth

As previously reported, dialysis patients had lower median height $\mathrm{z}$-scores than transplanted patients, but also only constitute approximately a fifth of the population. Median height $\mathrm{z}$-scores were very comparable between centres for both transplant and dialysis patients, especially when completeness and confidence intervals are taken into account. The inclusion of 16-18 year olds has not altered the median height $\mathrm{z}$-scores suggesting that the older patients are faring no worse in growth.

Over the last 15 years, the overall median height $\mathrm{z}$ score at RRT start is -1.4 , demonstrating the impact of a chronic disease in childhood and opportunities to improve growth at earlier stages of chronic renal failure. It is interesting to note that the median height $\mathrm{z}$-score for most transplant patients at five years was nearly the same as that at start, so despite the need for RRT, patients maintain their height, with the youngest transplant patients improving their height $\mathrm{z}$-score from a lower value at RRT start.

The information on use of growth hormone remained difficult to interpret due to a high proportion of missing data, and also there are many interventions to improve growth (other than growth hormone therapy) which the UKRR does not collect. Further, in situations where use of growth hormone is not recommended (such as in newly transplanted patients and in those demonstrating catch up growth) adjustment is not made in the analyses.

While the median weight $\mathrm{z}$-score for transplant patients is quite close to that of the healthy population, the data for dialysis patients show that they were more underweight. As dialysis patients and transplant patients were both shorter on average than their healthy peers, this meant that transplant patients had a higher BMI than their healthy peers with dialysis patients having a relatively normal BMI. It would be interesting to relate BMI to the use or not of steroids post transplantation.

Adding height and weight to the quarterly data (which some centres are already providing) would allow calculation of growth rates.

\section{Cardiovascular risk factor evaluation}

The analysis of SBP across different centres in 2014 continued to show some differences between centres although overall there has been some improvement in SBP levels. An investigation to understand and identify specific factors in transplant patients that have helped some centres achieve improved BP control is recommended.
In terms of the SBP standard, statistically fewer girls, South Asians and dialysis patients achieved the target. Further analysis also suggests primary renal diagnosis is important with metabolic and tubulo-interstitial primary renal diagnoses being associated with higher SBP. Further analysis regarding this is planned for the next Annual Report.

The prevalence of CVRFs was unchanged with 2014 data and the inclusion of 16-18 year olds, and although only data on half the patients is included it is consistent with previous evidence, including pre-dialysis CKD cohorts [8-9]. Current data highlights concern regarding this cohort. Last year the analysis showed hypertension to be the most prevalent CVRF at 48\% [10]. The data including the older patients now shows being both overweight and having hypercholesterolaemia were the most common at $44 \%$, secondary to higher BMIs in the 1618 year olds. This suggests that weight should be a specific target for intervention in the older patients.

\section{Laboratory and clinical indices}

Annual data regarding attainment of standards for laboratory measures was similar to previous years for haemoglobin, ferritin, calcium, phosphate, PTH and bicarbonate. The proportion of dialysis patients achieving the standards was rather low; however over-interpretation of single measurements of variable completeness from a small proportion of the cohort should be avoided.

The aim is to be able to report quarterly data for all laboratory indices for all centres which will indicate whether the standard achievements based on annual data are indeed accurate.

\section{Future work}

The goals of the paediatric UKRR remain the reporting of quarterly data for all paediatric renal centres, improving data extracts and then combining the adult and paediatric UKRR databases.

\section{Acknowledgement}

Thanks are expressed to Kidney Research UK and the British Kidney Patient Association whose contribution through the Tony Wing award contributed to the production of this chapter.

Conflicts of interest: the authors declare no conflicts of interest 


\section{References}

1 Renal Association standards, 3rd edition, $2002 \mathrm{http}$ ://www.renal.org/docs/ default-source/guidelines-resources/Renal_Association_Standards_3rd_ Edition_2002-2007.pdf?sfvrsn=0 (last accessed 24th September 2015)

2 TJ Cole, KM Flegal, D Nicholls, AA Jackson. Body Mass Index cut offs to define thinness in children and adolescents: international study. $B M J$ 2007;335(7612):194

3 Freeman JV CT, Chinn S et al. Cross sectional stature and weight reference curves for the UK, 1990. Arch Dis Child 1995;73:17-24

4 BAPN Standards for Hypertension in Paediatric Renal Transplant Recipients, $2011 \mathrm{http} / /$ www.renal.org/docs/default-source/special-interestgroups/bapn/clinical-standards/bapn-standards-for-hypertension-in-renaltransplant-recipients.pdf?sfvrsn=2 (last accessed 24th September 2015).

5 National High Blood Pressure Education Program Working Group on High Blood Pressure in Children and Adolescents. The Fourth Report on the Diagnosis, Evaluation, and Treatment of High Blood Pressure in Children and Adolescents. Pediatrics 2004;114(2):555-76

6 Expert panel on integrated guidelines for cardiovascular health and risk reduction in children and adolescents: summary report. Pediatrics. 2011 Dec; 128(suppl 5):S213-56. doi: 10.1542/peds.2009-2107C
7 NICE clinical guideline 114. Anaemia management in people with chronic kidney disease. London: National Institute for Health and Clinical Excellence, 2011

8 Wilson AC, Schneider MF, Cox C, Greenbaum LA, Saland J, White CT, Furth S, Warady BA, Mitsnefes MM. Prevalence and Correlates of Multiple Cardiovascular Risk Factors in Children with Chronic Kidney Disease. Clin J Am Soc Nephrol. 2011 Dec; 6(12):2759-65. doi: 10.2215/ CJN.03010311

9 Mitsnefes M. Cardiovascular Disease in Children with Chronic Kidney Disease. J Am Soc Nephrol 23: 578-585, 2012. doi: 10.1681/ASN. 2011111115

10 Hamilton AJ, Pruthi R, Maxwell H, Casula A, Braddon F, Inward C, Lewis M, O’Brien C, Stojanovic J, Tse Y, Sinha MD. UK Renal Registry 17th Annual Report: Chapter 9 Clinical, Haematological and Biochemical Parameters in Patients Receiving Renal Replacement Therapy in Paediatric Centres in the UK in 2013: National and Centre-specific Analyses. Nephron. 2015;129(suppl 1):209-22. doi: 10.1159/000370279 
